\title{
Construction and Research on the Teaching Effectiveness Model of Undergraduates' Social Practice Based on Matrix Theory and Vector Analysis
}

\author{
Rui Dai \\ Anhui Sanlian University, Hefei, China
}

\begin{abstract}
Keywords: effectiveness model; correlation coefficient; similarity measure; matrix theory; vector analysis; social practice
\end{abstract}

\begin{abstract}
. the primary content of institutions of higher learning in our country is social practice, which is not only used to train graduates, but also it is one of the main ways of improving the students' theoretical knowledge. This helps students to understand and realize the theory, which is related to practice. Social practice is very important, and it is also difficult to be achieved. With the undergraduates' employment situation becoming more and more severe, colleges' social practice is more difficult to carry out .This paper attaches to the Chinese colleges' social practice teaching situation, it applies for the former successful practice teaching experience and puts current social practice into effect, it is also used to study the inevitable trend of social practice teaching. According to the analysis of the individual practice effect, it opens up new ways for the development of the Chinese university students' social practice teaching by constructing the practical teaching management system.
\end{abstract}

\section{Introduction}

The theory is with practice is the Party's fine style, social practice is the basis of testing theory whether or not it is correct. When theoretical guidance and practical teaching are conjunct, it is of great significance to enhance the contemporary college students' social responsibility, whose mission is to achieve the common beliefs and ideals of the great national rejuvenation .Currently, there are some scholar teachers whose research and insights are applied in certain areas. For example, Wang Xiaoyun and Wei Caixia operate on the procedures based on the Social Practice Teaching of "Two Courses"[1].According to its political, ideological, teaching, manage mental characteristics etc, it starts from the class "Practice Teaching and designs appropriate principles of building a decisive support system, as well as protects the completion of the practice smoothly; Yu Xiuqin and Liu Junying's long-term mechanism of the innovative universities' social practice teaching,which starts from our colleges' social status as well as emphasizes a series of weak links in teachings. It is an urgent need to create the long-term practice teaching mechanism and to solve social needs of college students' practical ability; With the innovation being in practice, $\mathrm{Pu}$ Xiaodong and $\mathrm{Yu}$ Hongjun propose the ideological culture, and they use science and technology to enhance the urgent needs. Students choose to make a unique exposition of the students' social practice on the fundamental purpose, especially in the era of social practice ;Tao Zunshi's analysis of practical teaching model based on theoretical systems ,he analyzes the harmonious relations between the elements of practical education management system, various laboratories, practical basis, virtual internship systems of the practical teaching and the blend of realistic and long-term goals, then he builds a comprehensive practical teaching model ;Gao Yuan and other experts point out that the social practice in college students' political socialization is inseparable from the ideological and political education of college students' practice. It is combined with the historical background of educational innovation, which is specified in the current promotion and adoption for the new ideas of innovative practice teaching $[2,3]$.When teachings of undergraduates' social practice are improved, they are adhered to establish a solid practical ideas; With the ideological and political literacy improving, that theory is with practice will increase the importance of enthusiasm and understanding 
of the social practice[4]. Make sure that every university student can participate in practice, and they are able to benefit from practical action who put books on theoretical knowledge into practice.

\section{The status and cognition of current college students' social practice teaching}

The status of current college students' social teaching practice

There are varieties of social practice among college students, such as volunteers, research activities, community programs, work-study, etc. From their own schools' and regional characteristics, a variety of colleges and universities organize some social survey, charitable and social activities, they start from the four sides of science, education, civilization, health, and then they guide the students to think reasonably. Their efforts are to promote contemporary advanced theoretical guidelines as well as to establish a correct outlook on life and to build values for colleges. With the colleges' social and innovative practice teaching improving, the form of social practice among the college students is no longer single, which is combined with practical guiding ideology[5].And they provide a more diverse form of social practice and innovative ideas .As shown in Figure 1.

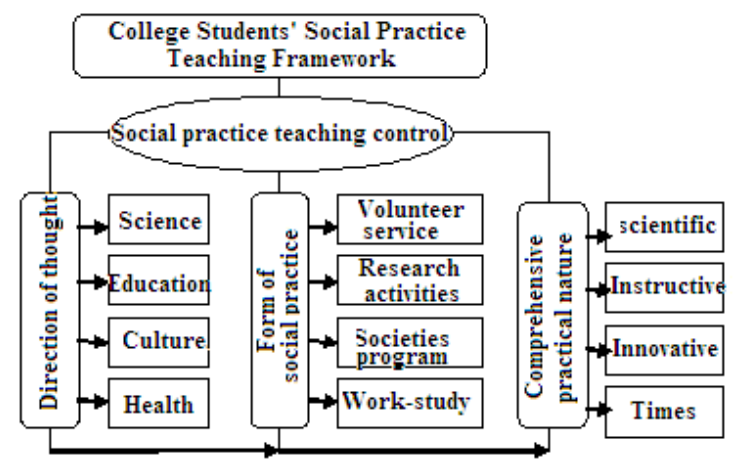

Figure 1. College students' social practice teaching system

According to the construction of the college students' social practice teaching system, researchers use scientific basis and efficient countermeasures to improve students ' enthusiasm of participation, which appears in social practice and their social practice teaching organizational system. It aims to enrich students' social practice connotation and the degree of the students' associative activities and the profession. Finally, they carry out social practice teaching work, etc fully.

\section{Current college students' social practice teaching cognition}

The formation of the practical teaching cognition goes through a long historical process. It starts from the basic guiding ideology, and constantly sums up experience in teaching, and innovates relative theories based on practice, and then applies theory to practical activities[6]. According to the process of 'practice - theory - practice', ultimately, a mature scientific practice teaching's cognitive theory is formed. A cognitive system is built for college students' social practice teaching and it helps teachers to guide the students to carry out practical activities better .As shown in Figure 2.

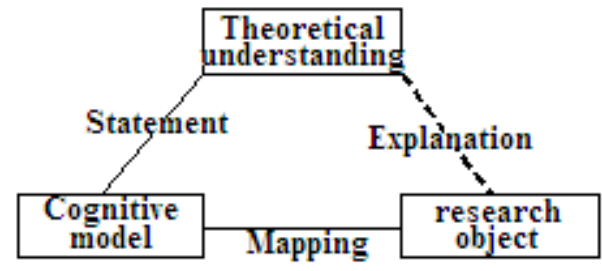

Figure 2. Practical teaching cognitive structure 
According to the Figure 2, it is known that the practical teaching is composed by cognitive theories, cognitive model and the research object, and they interact with each other. This produces three important stages of the practical teaching cognition, and enhances theoretical basis for the construction of university students' social practice teaching cognitive system. $\vec{A}$ is defined as a cognitive complexity theory, according to the $\vec{B}=\nabla \times \vec{A}$, namely[7]:

$$
\nabla \times\left(\vec{E}+\frac{\partial}{\partial t} \vec{A}\right)=0
$$

$\varphi_{\text {is defined as the research object correlation coefficient, namely: }}$

$$
\nabla \times\left(\vec{E}+\frac{\partial}{\partial \boldsymbol{t}} \vec{A}\right)=0
$$

, when the theory of cognitive complexity is combined with the

relationship of the research object's correlation coefficient, it is called the teaching cognitive

$$
\text { analysis } \vec{A}_{-} \varphi \text { : }
$$

Namely:

$$
\nabla^{2} \vec{A}-\mu \sigma \frac{\partial \vec{A}}{\partial t}=-\mu \vec{J}_{f}
$$

When the research object's correlation coefficient is mapped to cognitive model,the relationship is shown as[8]:

$$
\nabla^{2} \varphi=-\rho / \varepsilon
$$

According to the analysis of the research object's correlation coefficient and cognitive model , standard conditions are summarized :

$$
\nabla^{2} \varphi=-\rho / \mathcal{E}
$$

When the social practic teaching reform deepens, they require that the university students' social practice are not only mere formalities, but also the content of the social practice should be enriched by putting the teenagers' great mission in each country, the ways and methods of innovative social practice activities are also combined with the spirit of the age.

\section{Analysis of the student's individual practice effect}

There are varieties of social practice teaching model, the countries pay attention to the practical education teaching, and the teaching work has made a great progress. The cultivation of contemporary undergraduates' social practice is roughly divided into four types of tour, theme activities, work study and investigation research, a related practice project type and practical investigation are carried out,the investigation tests 1000 college students in grade 2011-2012 by annual social practice sampling questionnaire, and as shown in Table 1.

TABLE I. RESULTS QUESTIONNAIRE OF STUDENTS' SOCIAL PRACTICE

\begin{tabular}{|c|l|l|l|l|}
\hline \multirow{2}{*}{ grade } & \multicolumn{4}{|c|}{ Practice project } \\
\cline { 2 - 5 } & $\begin{array}{l}\text { Sight } \\
\text { seeing }\end{array}$ & $\begin{array}{c}\text { Theme } \\
\text { activities }\end{array}$ & Work-study & $\begin{array}{c}\text { Investigation } \\
\text { research }\end{array}$ \\
\hline
\end{tabular}




\begin{tabular}{|l|l|l|l|l|}
\hline freshman & 110 & 89 & 35 & 16 \\
\hline Sophomore & 107 & 70 & 51 & 22 \\
\hline junior & 61 & 90 & 68 & 31 \\
\hline senior & 22 & 45 & 93 & 90 \\
\hline
\end{tabular}

According to the results of students' social practice ,the survey finds that the school always implements social practice teaching training plans: Combining with the local cultural characteristics, they carry out relevant tour activities among the junior students actively, and enrich students' extracurricular cultural knowledge, as well as standardize the report's writing format. According to their own school-running characteristics, they define celebrations as the theme of the commemorative activities, and guide students in lower grades to establish school motto for faith and the correct outlook on life as soon as possible. Meanwhile, they also improve the students' writing level. By comparing the freshman and senior students who participate in social practice, the results can be known, as shown in Figure 3.

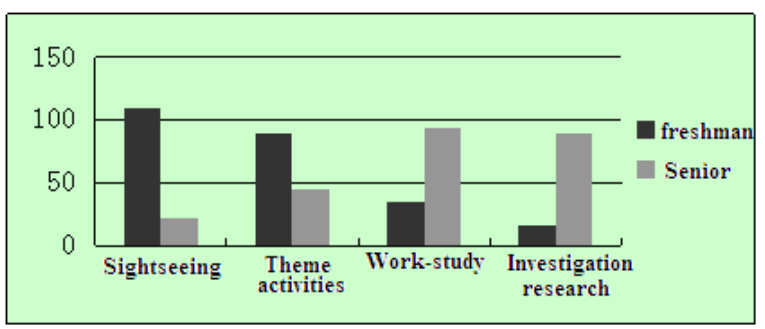

Figure 3. The comparison between freshman and senior students who participate in social practice

The schools provide more appropriate part-work and part-study systems of practical opportunities for poor students, and carry out relevant students' activities. They develope students' professional skills fully, and guide the contemporary college students to understand social needs and national present basic national conditions in practice, as well as inspire the students' learning thinking, and then enhance the learning initiative and enthusiasm. Combined the characteristics of schools and the resources with nearby principle, they organize the senior graduates to visit the company and factory and let them study research activities. In order to understand the whole operation, the basic principle of factory production is given priority. At the same time, the understanding of the development of history and the influence of production are put on the future prospects, they improve students' social practice ability on the basis of the combination between theory and practice.

\section{Management system of social practice teaching}

The method of teaching management evaluation has a wide range of applications in the social practice teaching, which is complicated and has the integrity and multiple attributes. It is the powerful basis that evaluates social practice teaching achievements accurately and analyzes the results of college students' social practice, the guidance of the theoretical teaching form $\left(x^{\prime}, y^{\prime} z^{\prime}\right)$ distributes in the production of practical teaching form $(x, y, z)$,it can be expressed as[9]:

$$
V(x, y, z)=\frac{1}{4 \pi \varepsilon} \int_{v^{\prime}} \frac{\rho_{v}\left(x^{\prime}, y^{\prime}, z^{\prime}\right) d v^{\prime}}{R} \text {... }
$$

Essentially, $\rho_{v}\left(x^{\prime}, y^{\prime} z^{\prime}\right)$ is the teaching expected result, $R$ is an uncertain factor between $(x, y, z)$ and $\left(x^{\prime}, y^{\prime} z^{\prime}\right)$. However, $\rho_{v}\left(x^{\prime}, y^{\prime}, z^{\prime}\right)$ is usually difficult to estimate, and the actual teaching result is given in pointed time. Therefore, in order to find out the teaching effect coefficient under the cases of different social practice activities, $\rho_{v}\left(x^{\prime}, y^{\prime} z^{\prime}\right)$ must be roughly estimated. 
Put $\rho_{v}\left(x^{\prime}, y^{\prime} z^{\prime}\right)$ into one of the conditions :

$$
\rho_{v}\left(x^{\prime}, y^{\prime} z^{\prime}\right)=\alpha_{1} \rho_{1}\left(x^{\prime}, y^{\prime} z^{\prime}\right)+\alpha_{2} \rho_{2}\left(x^{\prime}, y^{\prime} z^{\prime}\right)+\cdots+\alpha_{n} \rho_{n}\left(x^{\prime}, y^{\prime} z^{\prime}\right)=\sum_{i=1}^{n} \alpha_{i} \rho_{i}\left(x^{\prime}, y^{\prime} z^{\prime}\right) \text {. . . }
$$

Whereas $\rho_{i}\left(x^{\prime}, y^{\prime} z^{\prime}\right)$ is the expected results' similarity measure, ${ }^{\alpha}$ is the undetermined coefficient, when the type (6) is substituted by the type (5), the result is [10]:

$$
\begin{gathered}
V_{j}=V\left(x_{j}, y_{j}, z_{j}\right)=\frac{1}{4 \pi \varepsilon} \int_{v^{\prime}} \frac{\sum_{i=1}^{n} \alpha_{i} \rho_{i}\left(x^{\prime}, y^{\prime} z^{\prime}\right) d v^{\prime}}{|R|} . \\
V_{j}=\sum_{i=1}^{n} \alpha_{i} \frac{1}{4 \pi \varepsilon} \int_{v_{i}} \frac{\rho_{i}\left(x^{\prime}, y^{\prime} z^{\prime}\right) d v_{i}^{\prime}}{\left|R_{j i}\right|} \ldots
\end{gathered}
$$

On the basis of the practical teaching, the cognitive structure is analyzed. Combined with the university students' social practice teaching system, they set up the model of "information attached to space", and work out the effected factors and the conditional attributes under the corresponding conditions, and analyze each factor's correlation-ship. A more targeted college students' social practice teaching management system will also be built up further .Here, $j=1,2, \cdots, n$, in view of the college students' social practice activities, so they consider $\rho_{i}\left(x^{\prime}, y^{\prime} z^{\prime}\right)$ as the effect of coefficient, $V(x, y, z)$ can be represented by the comprehensive effect coefficient under the following special conditions, namely[11]:

$$
\begin{gathered}
V_{j i}=\frac{1}{4 \pi \varepsilon} \int_{v_{i}} \frac{\rho_{i}\left(x^{\prime}, y^{\prime} z^{\prime}\right) d v_{i}^{\prime}}{\left|R_{j i}\right|} \quad j=1,2, \cdots, n \text {. So: } \\
V_{j}=\sum_{i=1}^{n} \alpha_{i} V_{j i} \\
. \underline{1}
\end{gathered}
$$

As $V(x, y, z)$ is expected before the practice, so the unknown coefficient $\alpha_{1}, \alpha_{2}, \cdots, \alpha_{n}$ can be expressed as[12]:

$$
\begin{gathered}
V_{1}=\alpha_{1} V_{11}+\alpha_{2} V_{12}+\cdots+\alpha_{n} V_{1 n} \\
V_{2}=\alpha_{1} V_{21}+\alpha_{2} V_{22}+\cdots+\alpha_{n} V_{2 n} \\
\vdots \\
V_{j}=\alpha_{1} V_{j 1}+\alpha_{2} V_{j 2}+\cdots+\alpha_{n} V_{j n} \\
\vdots \\
V_{n}=\alpha_{1} V_{n 1}+\alpha_{2} V_{n 2}+\cdots+\alpha_{n} V_{n n} 1 !
\end{gathered}
$$

The following form can be identified as : 


$$
\left[\begin{array}{c}
V_{1} \\
\vdots \\
V_{j} \\
\vdots \\
V_{n}
\end{array}\right]=\left[\begin{array}{ccccc}
V_{11} & & V_{1 j} & & V_{1 n} \\
\vdots & \ddots & \vdots & \ddots & \vdots \\
V_{j 1} & & V_{j j} & & V_{j n} \\
\vdots & \ddots & \vdots & \ddots & \vdots \\
V_{n 1} & & V_{n j} & & V_{n n}
\end{array}\right]\left[\begin{array}{c}
\alpha_{1} \\
\vdots \\
\alpha_{j} \\
\vdots \\
\alpha_{n}
\end{array}\right]_{1} .
$$

After they find out $\alpha$, and use the type 5, then the expected results' similarity measure $\rho_{i}\left(x^{\prime}, y^{\prime} z^{\prime}\right)$ can be determined. Then they can use type 6 to predict the effect coefficient to reach the goal of judging the social practice quality, more scientific and reasonable countermeasures are put forward to improve the social practice teaching system.

\section{Conclusion}

In universities, compared with the curriculum theory teaching, the implementation of the social practice teaching still has certain difficulties, this is due to the fact that the traditional teaching mode only emphasizes the theory but oversees its combination with practice for a long time. Above all, from the current situation of Chinese colleges' social practice teaching, social practice teaching rule can be found on the basis of the former practical teaching experience. It provides a strong scientific basis for the development of Chinese university students' social practice, making social practice teaching and the theoretical teaching benefit from each other.

\section{Acknowledgement}

The paper is one of the closed results of the provincial quality project teaching and researching topic. Project name: Research on the cultivation of oral communicative ability for English major in application-oriented universities, Code: 2012jyzm587.

\section{References}

[1] Wang Xiaoyun, Wei Caixia. Research on "Two Courses" Social Practice Teaching Procedures . Journal of Jianghan University,2012(9):17-21.

[2] Yu Xiuqin, Liu Junying. The Long-term Mechanism of Innovative Universities' Social Practice Teaching .Education and Vocation,2011 (11):76-79.

[3] Pu Xiaodong, Yu Hongjun. Practical Innovation: College Students' Choice about Social Practice, Cultural and Educational Material,2012(12):45-48.

[4] Tao Zunshi. The Analysis of Practical Teaching Model Construction Based on System Theory Modern Distance Education Research,2009(9):55-59.

[5] Wang Xuejian, Li Yongjie. The Discussion of the Colleges' Ideological and Political Theory Based on the Social Practice Teaching System. The Guidance of Ideological and Theoretical Education, 2012(4):115-119..

[6] Wang Xuejian, Li Yongjie. The Discussion of the Colleges' Ideological and Political Theory Based on the Social Practice Teaching System. The Guidance of Ideological and Theoretical Education,2012 (3):39-45.

[7] Duan Lixin.Research on Contemporary College Students' Political Socialization. Jilin University,2007.

[8] Cheng Ying. The Problems and Countermeasures on Contemporary College Students' Political Socialization . Northeast Normal University,2006. 
[9] Zhou Aiguo .The Cultivation of College Students' Social Practice Ability, Huai'an College in Jiangsu Province. East China Normal University. 2010

[10] Huang Ping. Discussions of College Students' Social Practice Evaluation System . Education and Vocation,2013(1):56-59.

[11] Qian Xuesen. Theoretical System Engineering. Hunan Science and Technology Publishment Press,2009.:147-159

[12] Sociology of Education Hiroshima University.Toward a Sociological Diagnosis of Community's Education. Journal of Educational Sociology,2009(12):106-109. 